\title{
ДОСЛІДЖЕННЯ ЗАЛЕЖНОСТІ ПОХИБКИ ПОЗИЦІОНУВАННЯ ПНЕВМАТИЧНОГО ПРИВОДУ ВІД ПАРАМЕТРІВ ЙОГО РОБОТИ
}

\begin{abstract}
Анотація: Аналізуються експериментальні, отримані шляхом проведення повнофакторного експерименту, данні для визначення залежності похибки позиціонування пневматичного приводу від параметрів його роботи - тиску в циліндрі пневмоприводу, швидкості руху маніпулятора, швидкості гальмування.

Ключові слова: похибка позиціонування, пневматичний привід, повнофакторний експеримент.
\end{abstract}

\section{Вступ}

Кожен пневматичний привід (як і інші види приводів) має деяку похибку позиціонування. Як правило, ця характеристика приводу є параметром конкретної моделі і визначаеться максимальною похибкою позиціонування. На практиці, середньостатистична величина цієї похибки залежить від параметрів роботи самого приводу, таких як тиск в циліндрі пневмоприводу, швидкість руху маніпулятора, швидкість гальмування, зношеність деталей, температура, тощо. Для визначення залежності похибки позиціонування від параметрів роботи приводу використовують теорію планування експерименту, попередньо вибравши параметри, залежність від яких необхідно визначити (фактори). Коли залежність встановлена, аналіз отриманого результату дозволяє прогнозувати похибки позиціонування виконавчих органів маніпулятора промислового робота, і тим самим, підвищити надійність його роботи.

\section{Постановка експерименту}

Експеримент проводився на стенді, що містить штоковий позиційний пневмопривід з наступними характеристиками: робочий хід пневмоприводу 500 мм, діаметр поршня 80 мм, габарити експериментального стенду 1500 x $400 \times 180$ мм; та контрольно-вимірювальну апаратуру для вимірювання тиску, швидкості та швидкості гальмування штоку пнемоциліндра.

В якості факторів, що здійснюють вплив на точність позиціонування маніпулятора, прийняті такі параметри роботи пневматичного приводу, як тиск в циліндрі пневмоприводу $(P)$, швидкість руху маніпулятора $\left(V_{M}\right)$, швидкість гальмування $\left(V_{\Gamma}\right)$. Інші фактори стабілізовані.

Таким чином, в результаті дослідження необхідно встановити значення факторів $P, V_{M}$ та $V_{\Gamma}$, що забезпечують мінімальне значення похибки позиціонування $\Delta=f\left(P, V_{M}, V_{\Gamma}\right) \rightarrow \min$.

В якості інтервалів зміни факторів $P, V_{M}$ та $V_{\Gamma}$ обрано наступні значення:

(c) М.М. Поліщук, А.В. Землянкін, 2012 


$$
\begin{gathered}
P=5.5 \div 8.0 \text { бap; } \\
V_{M}=0.6 \div 0.9 \mathrm{M} / \mathrm{c} \\
V_{\Gamma}=0.04 \div 0.10 \mathrm{M} / \mathrm{c} .
\end{gathered}
$$

Введемо позначення: $\Delta=y ; P=\tilde{x}_{1} ; V_{M}=\tilde{x}_{2} ; V_{\Gamma}=\tilde{x}_{3}$;

Складемо матрицю експерименту типу $2^{3}$, в якій значення всіх фракторів знаходяться в усіх можливих комбінаціях і проведемо вимірювання в цих точках. Для побудови моделі потрібно забезпечити необхідну відтворюваність результатів експериментів. Для цього обрано число повторюваних досліджень $r=2$.

Результати експериментів

Таблиця 1

\begin{tabular}{|c|c|c|c|c|c|}
\hline № & $\tilde{x}_{1}$ & $\tilde{x}_{2}$ & $\tilde{x}_{3}$ & $y_{1}$ & $y_{2}$ \\
\hline 1 & 5.5 & 0.6 & 0.04 & 240 & 245 \\
\hline 2 & 5.5 & 0.6 & 0.10 & 262 & 255 \\
\hline 3 & 5.5 & 0.9 & 0.04 & 305 & 320 \\
\hline 4 & 5.5 & 0.9 & 0.10 & 317 & 305 \\
\hline 5 & 8.0 & 0.6 & 0.04 & 332 & 340 \\
\hline 6 & 8.0 & 0.6 & 0.10 & 342 & 335 \\
\hline 7 & 8.0 & 0.9 & 0.04 & 350 & 365 \\
\hline 8 & 8.0 & 0.9 & 0.10 & 372 & 375 \\
\hline
\end{tabular}

Зведемо матрицю експерименту до нормованої, в якій верхнім значенням факторів відповідае +1 , а нижнім -1 . В загальному випадку $x_{i}=\frac{2 \tilde{x}_{i}-\tilde{x}_{i \max }-\tilde{x}_{i \min }}{\tilde{x}_{i \max }-\tilde{x}_{i \min }}$. Результати представлено у таблиці 2 . Також, додамо стовбці з середнім значенням похибки по двом експериментам, коефріцієнт вільного члена моделі та коефіцієнтів взаємодії факторів.

Загальне рівняння з урахуванням усіх членів взаємодії факторів записуеться в кодованих змінних:

$$
y=b_{0}+b_{1} x_{1}+b_{2} x_{2}+b_{3} x_{3}+b_{12} x_{1} x_{2}+b_{13} x_{1} x_{3}+b_{23} x_{2} x_{3}+b_{123} x_{1} x_{2} x_{3}
$$

Визначення коефіціентів моделі проводиться за формулою (2)

$$
\begin{gathered}
b_{i}=\frac{\sum_{v=1}^{n} x_{i v} \bar{y}_{v}}{n} \\
y=316.25+35.125 x_{1}+22.375 x_{2}+4.125 x_{3}-8.25 x_{1} x_{2} \\
+0.5 x_{1} x_{3}-0.5 x_{2} x_{3}+3.875 x_{1} x_{2} x_{3}
\end{gathered}
$$

\section{Визначення дисперсії відтворюваності}

Дисперсія відтворюваності визначаеться за формулою (4). 


\begin{tabular}{|c|c|c|c|c|c|c|c|c|c|c|c|}
\hline № & $x_{0}$ & $x_{1}$ & $x_{2}$ & $x_{3}$ & $x_{1} x_{2}$ & $x_{1} x_{3}$ & $x_{2} x_{3}$ & $x_{1} x_{2} x_{3}$ & $y_{1}$ & $y_{2}$ & $\bar{y}$ \\
\hline 1 & +1 & -1 & -1 & -1 & +1 & +1 & +1 & -1 & 240 & 245 & 242.5 \\
\hline 2 & +1 & -1 & -1 & +1 & +1 & -1 & -1 & +1 & 262 & 255 & 258.5 \\
\hline 3 & +1 & -1 & +1 & -1 & -1 & +1 & -1 & +1 & 305 & 320 & 312.5 \\
\hline 4 & +1 & -1 & +1 & +1 & -1 & -1 & +1 & -1 & 317 & 305 & 311 \\
\hline 5 & +1 & +1 & -1 & -1 & -1 & -1 & +1 & +1 & 332 & 340 & 336 \\
\hline 6 & +1 & +1 & -1 & +1 & -1 & +1 & -1 & -1 & 342 & 335 & 338.5 \\
\hline 7 & +1 & +1 & +1 & -1 & +1 & -1 & -1 & -1 & 350 & 365 & 357.5 \\
\hline 8 & +1 & +1 & +1 & +1 & +1 & +1 & +1 & +1 & 372 & 375 & 373.5 \\
\hline
\end{tabular}

$$
S^{2}\{y\}=\frac{\sum_{v=1}^{n} \sum_{j=1}^{r}\left(y_{v j}-\bar{y}_{v}\right)^{2}}{N(r-1)}
$$

Таким чином, $S^{2}\{y\}=\frac{395}{8(2-1)}=49.375, S\{y\}=7.027$.

\section{Перевірка однорідності дисперсії за критерієм Кохрена}

$$
G=\frac{S_{v \max }^{2}}{S_{v}^{2}}=\frac{56.25}{395}=0.142
$$

Для $f_{v \max }=r-1=2-1=1 ; f_{\text {знал }}=N=8 ; \alpha=0.05$.

За таблицею визначаємо критичне значення критерія Кохрена: $G_{\kappa p}=$ $0.6798, G<G_{\kappa p}$.

Отже, гіпотеза про однорідність моделі приймається.

\section{1 Перевірка значимості коефіцієнтів регресії}

$$
\begin{gathered}
S^{2}\left\{b_{i}\right\}=\frac{S^{2}\{y\}}{N r}=\frac{49.375}{8 \cdot 2}=3.086 ; \\
S\left\{b_{i}\right\}=1.757 .
\end{gathered}
$$

Критичне значення критерію Стьюдента для $f_{E}=N(r-1)=8$ та $\alpha=0.05$ знаходимо за таблицею:

$$
t_{\kappa p}=2.31 \text {. }
$$

Половина довжини довірчого інтервалу:

$$
\Delta b_{i}=t_{\kappa p} S\left\{b_{i}\right\}=2.31 \cdot 1.757=4.058 .
$$

Коефіцієнт вважається значимим, якщо $\left|b_{i}\right| \geqslant \Delta b_{i}$. В рівнянні (3) такими коефіцієнтами є:

$$
\left|b_{0}\right|=316.25 ;\left|b_{1}\right|=35.125 ;\left|b_{2}\right|=22.375 ;\left|b_{3}\right|=4.125 ;\left|b_{12}\right|=-8.25 \text {. }
$$

В інших коефіцієнтів їх значення менше половини довірчого інтервалу. Тому їх можна відкинути без перерахунку інших.

В результаті, у кодованих змінних модель буде мати вигляд: 


$$
y=316.25+35.125 x_{1}+22.375 x_{2}+4.125 x_{3}-8.25 x_{1} x_{2}
$$

\section{Перевірка адекватності моделі}

Дисперсія адекватності

$$
S_{a \partial}^{2}=\frac{r}{N-m} \sum_{v=1}^{8}\left(\bar{y}_{v}-y_{v}\right)^{2},
$$

де $m=4$ - число членів апроксимуючого поліному.

Підставивши у формулу (5) значення $(+1)$ та $(-1)$, у відповідності до матриці планування, знайдемо розрахункове значення $\hat{y}_{v}$ та запишемо результати у таблицю 3 :

Таблиця 3

\begin{tabular}{|c|c|c|c|c|}
\hline$№$ досліду & $\bar{y}_{v}$ & $y_{v}$ & $\left(\bar{y}_{v}-y_{v}\right)$ & $\left(\bar{y}_{v}-y_{v}\right)^{2}$ \\
\hline 1 & 242.5 & 246.375 & -3.875 & 15.016 \\
\hline 2 & 258.5 & 254.625 & 3.875 & 15.016 \\
\hline 3 & 312.5 & 307.625 & 4.875 & 23.766 \\
\hline 4 & 311 & 315.875 & -4.875 & 23.766 \\
\hline 5 & 336 & 333.125 & 2.875 & 8.266 \\
\hline 6 & 338.5 & 341.375 & -2.875 & 8.266 \\
\hline 7 & 357.5 & 361.375 & -3.875 & 15.016 \\
\hline 8 & 373.5 & 369.625 & 3.875 & 15.016 \\
\hline \multicolumn{5}{|r}{} \\
\hline
\end{tabular}

$$
S_{a \partial}^{2}=\frac{2}{8-5} \cdot 124.125=82.75 .
$$

Критерій Фішера:

$$
F=\frac{S_{a \partial}^{2}}{S^{2}\{y\}}=\frac{82.75}{49.375}=1.676 .
$$

Критичне значення критерія Фішера для

$$
\begin{gathered}
f_{a \partial}=N-m=8-5=3 ; \\
f_{E}=N(r-1)=8(2-1)=8 ; \\
\alpha=0.05
\end{gathered}
$$

Знаходимо за таблицею критерія Фішера:

$$
F_{\kappa p}=8.84 \text {. }
$$

Умова $F<F_{\kappa p}$ виконуеться, отже, модель адекватна. 


\section{Розрахунок коефіціенту множинної кореляції}

В якості величини, що характеризує вклад коефіціентів регресії у рівняння моделі будемо використовувати коефіціент множинної кореляції, що визначаеться за формулою (7):

$$
R=\sqrt{1-\sum_{v}\left(\bar{y}_{v}-y_{v}\right)^{2} / \sum_{v}\left(\bar{y}_{v}-\bar{y}\right)^{2}}
$$

Величина $R$ може змінюватись від 0 до +1 . Якщо вклад, що вносить коефіцієнт регресії дорівнюе нулю, то $R=0$; якщо ж рівняння регресії повністю описуе результати експерименту, то $R=1$.

В результаті отримаємо:

$$
R=\sqrt{1-\frac{124.125}{14680.752}}=0.996 .
$$

Таким чином, рівняння регресії практично повністю описує результати експерименту.

\section{Перехід до моделі в натуральних змінних}

Виконуючи перехід до моделі в натуральних змінних, отримаємо:

$$
\begin{aligned}
& y=316.25+35.125\left(\frac{2 \tilde{x}_{1}-\tilde{x}_{1 \max }-\tilde{x}_{1 \min }}{\tilde{x}_{1 \max }-\tilde{x}_{1 \min }}\right)+22.375\left(\frac{2 \tilde{x}_{2}-\tilde{x}_{2 \max }-\tilde{x}_{2 \min }}{\tilde{x}_{2} \max -\tilde{x}_{2 \min } \tilde{x}_{2}}\right) \\
& +4.125\left(\frac{2 \tilde{x}_{3}-\tilde{x}_{3 \max }-\tilde{x}_{3 \min }}{\tilde{x}_{3} \max -\tilde{x}_{3 \min }}\right)-8.25\left(\frac{2 \tilde{x}_{1}-\tilde{x}_{1} \max -\tilde{x}_{1 \min }}{\tilde{x}_{1 \max }-\tilde{x}_{1 \min }}\right) \times\left(\frac{2 x_{2}-\tilde{x}_{2 \max }-\tilde{x}_{2 \min }}{\tilde{x}_{2} \max -\tilde{x}_{2} \min }\right)
\end{aligned}
$$

Остаточний результат у вихідних змінних:

$$
\Delta=-217.68+61.1 P+446.17 V_{M}+137.5 V_{\Gamma}-44 V_{M} V_{\Gamma}
$$

\section{Побудова графіків перерізів отриманої залежності}

Для отримання практично корисного результату побудуємо двовимірні графіки отриманої функціональної залежності, по яким на підприемстві можна швидко визначити необхідні параметри роботи пневмоприводу для отримання задовільного рівня похибки позиціонування маніпулятора.

Двовимірні графіки отримаємо як графіки залежності похибки позиціонування від тиску в циліндрі пневмоприводу, встановлюючи незмінними швидкість руху маніпулятора та швидкість гальмування. Побудуємо перерізи при трьох значеннях обох швидкостей (мінімальне, середне та максимальне) та отримаємо $3 \times 3=9$ графіків. Залежність похибки позиціонування від тиску в циліндрі пневмоприводу при швидкості гальмування $V_{\Gamma}=0.04 \mathrm{M} / \mathrm{c}, V_{\Gamma}=0.07 \mathrm{~m} / \mathrm{c}, V_{\Gamma}=0.10 \mathrm{~m} / \mathrm{c}$ наведено на рис. 1,2 та 3, відповідно.

\section{Висновки}

В результаті проведених експериментів отримана неповна квадратична модель виду $y=316.25+35.125 x_{1}+22.375 x_{2}+4.125 x_{3}-8.25 x_{1} x_{2}$.

По величині та знаку коефіцієнтів регресії можна зробити висновки про вплив параметрів приводу на величину похибки позиціонування. 
$V_{\mathrm{r}}=$ const $=0.04 \mathrm{M} / \mathrm{c}$

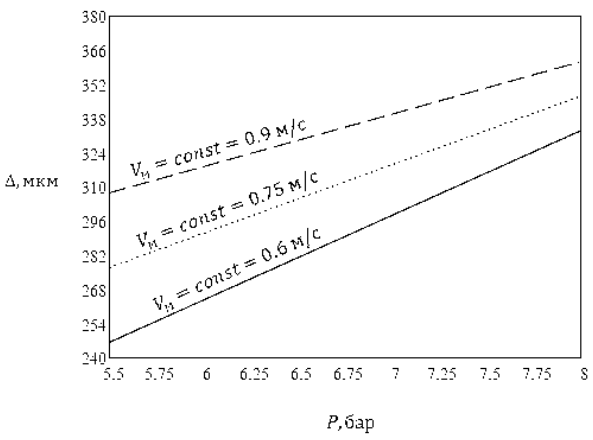

Рис. 1 -

$V_{\mathrm{r}}=$ const $=0.07 \mathrm{M} / \mathrm{c}$

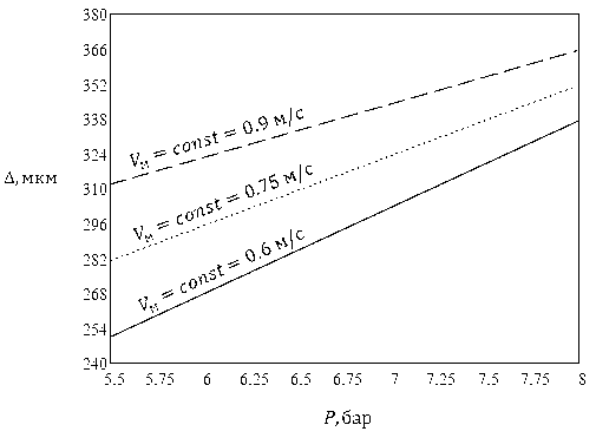

Рис. 2 -

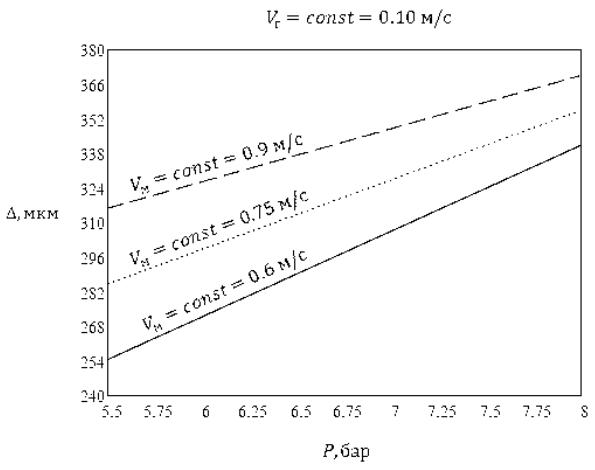

Рис. 3 - 
1. Якщо $b_{i}>0$ то збільшення $x_{i}$ викликае збільшення похибки позиціонування. Таким чином, збільшення тиску в циліндрі пневмоприводу, швидкості руху маніпулятора чи швидкості гальмування приводить до збільшення похибки позиціонування $\Delta$ причому ця похибка залежить головним чином від швидкості руху маніпулятора та тиску в циліндрі пневмоприводу.

2. Вплив змішаного добутку фракторів оцінюеться значимістю та знаком коеріцієнта $b_{i j}$. При $b_{i j}=b_{12}<0$ величина $\Delta$ буде зменшуватись, якщо $x_{1}$ та $x_{2}$ знаходяться одночасно на верхніх або нижніх рівнях.

3. Отримані перерізи графіків залежності похибки позиціонування від параметрів роботи пневмоприводу є практично корисним результатом, що може бути застосований на підприемствах для визначення похибки позиціонування маніпуляторів промислових роботів, що оснащенні пневматичними приводами.

\section{Література}

1. Оптимізація технічних рішень в машинобудуванні / Пляскін I.I. // М.: Машинобудування, 1982. - 176 с.

2. Статистичні методи планування експерименту в технікоекономічних дослідженнях / Вознесенський В.А. // М.: Статистика, 1974. - $192 \mathrm{c}$.

3. Математична теорія оптимальних процесів / Понтрягін Л.С., Болтянський В.Г., Гамкрелідзе Р.В., Мищенко Е.Ф. // М.: Наука, 1976. $392 \mathrm{c}$.

4. Планування промислових експериментів / Горський В.Г., Адлер Ю.П., Талалай А.М. // М.: Металургія, 1978. 351 с.

Отримано 25.05.2012 p. 